\title{
Cigarette Smoke: An Insight on Noncancerous Oral Manifestations
}

\author{
Hasan Baber ${ }^{1 *}$, Zunaira Rabbani ${ }^{2}$, Ambreen Sheraz ${ }^{3}$ and Zia Abbas ${ }^{4}$ \\ ${ }^{1}$ Assistant Professor, Dow University of Health Sciences, Pakistan
}

${ }^{2}$ Department of Periodontology, Baqai Medical University, Pakistan

${ }^{3}$ Private Dental Practioner, Pakistan

${ }^{4}$ Associate Professor, Dow University of Health Sciences, Pakistan

*Corresponding author: Hassan Baber, Assistant Professor, Dow University of Health Sciences, Karachi, Pakistan

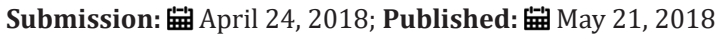

\begin{abstract}
Introduction: Oral lesions can occur due to number of factors such as trauma, infections, irritation, systemic diseases and oral consumption of tobacco. Changes associated in oral cavity as a result of smokeless tobacco are of utmost importance, and with such a high prevalence rate epidemiological studies must be carefully carried out. Present study is an effort to narrow the gap in determine prevalence of oral mucosal lesions among smokeless tobacco users of Pakistani Population.
\end{abstract}

Methodology: A cross-sectional study was conducted for a period of six months at Dental OPDs of Sindh, via aid of a validated custom-made questionnaire. Random sampling technique was adopted among patients attending dental OPDs, making using of OPEN API online software determining sample size as 289 , with limitation included exclusion of pregnant women, edentulous individuals, children under age of 18 years and those having oral manifestations associated with any systemic disease. Statistical analysis included logistic regression and chi-square for determine odds ratio and possible associations.

Results: Logistic regression model 71\% predicted discoloration of buccal mucosa 206 times in absence of any predictor variable. Discoloration of oral tissues was prevalent among individuals who chewed tobacco at least 5 times or more in a day. Periodontal associated damage was also prevalent among 5 times/day and more tobacco chewers, in line with similar studies elsewhere.

Conclusion: Study has demonstrated specific smokeless tobacco associated oral lesions. Further studies including other factors such as socioeconomic status, ethnicity and incorporating more number of participants including different provinces of Pakistan will help in further confirming our findings and report oral effects of frequency of smokeless tobacco at a national level.

Keywords: Smokeless tobacco; Discolouration; Lesions; OPDs

Abbreviation: OPD: Outpatient Department; SEOM: Standard Error of Mean; WHO: World Health Organization

\section{Introduction}

Oral cavity is susceptible to a plethora of variations with increasing age, change of environment and factors related to life patterns. Oral lesions can occur due to number of factors such as trauma, infections, irritation, systemic diseases and oral consumption of tobacco [1]. The latter is consumed in many forms with most prevalent form as smokeless tobacco and cigarette smoke. Prevalence of oral mucosal lesions as a result of factors such as tobacco is available for different countries but the information within that context cannot be always applicable to subcontinent population because of cultural, ethnic and demographic differences. Although efforts have been made by various researchers regarding establishment of oral mucosal lesions, but is meager in subcontinent literature [2]. Etiology for increased prevalence of oral cancer in South Asia has been investigated at some level, but as in case with most developing countries, lack of research infrastructure has become a stumbling block in studying risk factors and epidemiology of these conditions with respect to South Asia [3]. Among various risk factors, smokeless tobacco is highly associated with oral premalignant lesions and oral cancer. Tobacco has been used in smoke, inhaled and chewed forms for more than 500 years [4]. Tobacco use is and will persist as a global phenomenon.

Epidemiological studies have reported south Asia accounting for $90 \%$ of smokeless tobacco use among rest of the world (WHO report 2013). Estimates suggest around 100 million people 
consume tobacco in Indian Subcontinent alone [5]. Various forms of smokeless tobacco consumed in Pakistan and India include chewing form with a mixture of Gutkha, Khaini, beta nut and Mishri. Smokeless tobacco has around 28 carcinogens [6]. Thus, changes associated in oral cavity as a result of smokeless tobacco are of utmost importance, and with such a high prevalence rate epidemiological studies must be carefully carried out. Present study is an effort to narrow the gap in determine prevalence of oral mucosal lesions among smokeless tobacco users of Pakistani Population.

\section{Methodology}

\section{Study type}

Cross-sectional.

\section{Study design}

Observational.

\section{Study period}

Six months (Sept 2017- Feb 2018).

\section{Study location}

Dental OPDs of Sindh.

\section{Data collection}

Validated custom-made questionnaire (adapted from V Kasal et al.).

\section{Sample size}

300 (95\% confidence interval, 5\% SEOM) by use of open API) via Multistage sampling technique.

\section{Mean age of participants}

28 years.

\section{Exclusion criteria}

Edentulous Patients, known systemic disease induced oral manifestation, less than 18 years of age and pregnant women.

\section{Data interpretation}

SPSS version 23.0 .

\section{Data analysis}

Chi Square and Logistic Regression.

Population size was determined by number of patients attending dental OPDs of Sindh during a period of six months. The sample size turned up to be 300 which was close to similar related studies elsewhere. Response rate was 289/300 for participants. Oral examination was carried out using mouth mirror, explorer, cotton swabs and dental chair direct illumination by trained personnel. WHO (World health Organization guidelines were used in the methodological procedure of oral examination. Oral hygiene was calculated by Greene \& Vermillion [7] simplified oral hygiene index (OHI-S). Written consent was taken from all participants before the start of the study. Examination based on oral lesions included discoloration of mucosa, palate and floor of the mouth. Sociodemographic variables included age, education status and gender. To determine Odds ratio logistic regression analysis was used and for determining an association among oral lesions and different factors chi square analysis was used.

\section{Results}

Results of study are tabulated in graphs and tables below (Table 1-5 and Figure 1-6).

Table 1: Logistic regression model $71 \%$ predicted discoloration of buccal mucosa 206 times in absence of any predictor variable.

\begin{tabular}{|c|c|c|c|}
\hline \multirow{2}{*}{$\begin{array}{c}\text { Observed } \\
\text { Step 0 Discolored Buccal Mucosa }\end{array}$} & \multicolumn{2}{|c|}{ Predicted } & Percentage Correct \\
\cline { 2 - 4 } & \multicolumn{2}{|c|}{ Discolored Buccal Mucosa } \\
\hline Yes & Yes & 0 & 100 \\
\hline No & 206 & 0 & 0 \\
\hline Overall percentage & 83 & & 71.3 \\
\hline
\end{tabular}

Table 2: Logistic regression model 51\% predicted discoloration of labial mucosa 120 times in absence of any predictor variable

\begin{tabular}{|c|c|c|c|}
\hline \multirow{3}{*}{$\begin{array}{c}\text { Observed } \\
\text { Step 0 Discolored Labial Mucosa }\end{array}$} & \multicolumn{3}{|c|}{ Predicted } \\
\hline & \multicolumn{2}{|c|}{ Discolored Labial Mucosa } & \multirow[t]{2}{*}{ Percentage Correct } \\
\hline & Yes & No & \\
\hline Yes & 120 & 18 & 87 \\
\hline No & 108 & 13 & 10.7 \\
\hline Overall percentage & & & 51.4 \\
\hline
\end{tabular}


Table 3: Logistic Regression for discoloration of labial mucosa predicted Odds ratio of Betal nut chewing to cause 0.9 times more likely discoloration of buccal mucosa than cigarette smoke ( 0.7 times)

\begin{tabular}{|c|c|c|c|c|c|c|c|c|}
\hline & B & S.E. & Wald & df & Sig. & \multicolumn{2}{|c|}{$\operatorname{Exp(B)}$} & \multicolumn{2}{|c|}{ 95\% C.I. for EXP(B) } \\
\cline { 3 - 10 } & & & & & & & Lower & Upper \\
\hline Step 1a & -0.283 & 0.269 & 1.103 & 1 & 0.294 & 0.754 & 0.445 & 1.277 \\
\hline & -0.047 & 0.273 & 0.03 & 1 & 0.862 & 0.954 & 0.559 & 1.627 \\
\hline & 0.366 & 0.701 & 0.273 & 1 & 0.601 & 1.442 & & \\
\hline
\end{tabular}

a. Variable(s) entered on step 1: Cigarette, Betal Nut.

Table 4: Logistic regression model 55\% predicted no discoloration of floor of mouth in absence of any predictor variable.

\begin{tabular}{|c|c|c|c|}
\hline \multirow{2}{*}{$\begin{array}{c}\text { Observed } \\
\text { Step 0 Discolored floor of mouth }\end{array}$} & \multicolumn{2}{|c|}{ Predicted } & Percentage Correct \\
\cline { 2 - 4 } & Yes & No & 0 \\
\cline { 2 - 4 } & 0 & 130 & 100 \\
\hline Yes & 0 & 159 & 55 \\
\hline No & & & 0 \\
\hline
\end{tabular}

a. The cut value is .500

Table 5: Logistic Regression for discoloration of floor of mouth predicted Odds ratio of Betal nut chewing to cause 1.3 times more likely discoloration of floor of mouth than cigarette smoke (0.9 times).

\begin{tabular}{|c|c|c|c|c|c|c|c|c|c|}
\hline & & & & & & & & \multicolumn{2}{|c|}{ S5\% C.I. for EXP(B) } \\
\cline { 3 - 11 } & & & S.E. & Wald & df & Sig. & Exp(B) & Lower & Upper \\
\hline Step 1a & Cigarette & -0.004 & 0.255 & 0 & 1 & 0.986 & 0.996 & 0.604 & 1.641 \\
\hline & Betal Nut & 0.275 & 0.257 & 1.148 & 1 & 0.284 & 1.316 & 0.796 & 2.176 \\
\hline & Constant & -0.22 & 0.659 & 0.111 & 1 & 0.739 & 0.803 & \\
\hline
\end{tabular}

a. Variable(s) entered on step 1: Cigarette, Betal Nut.

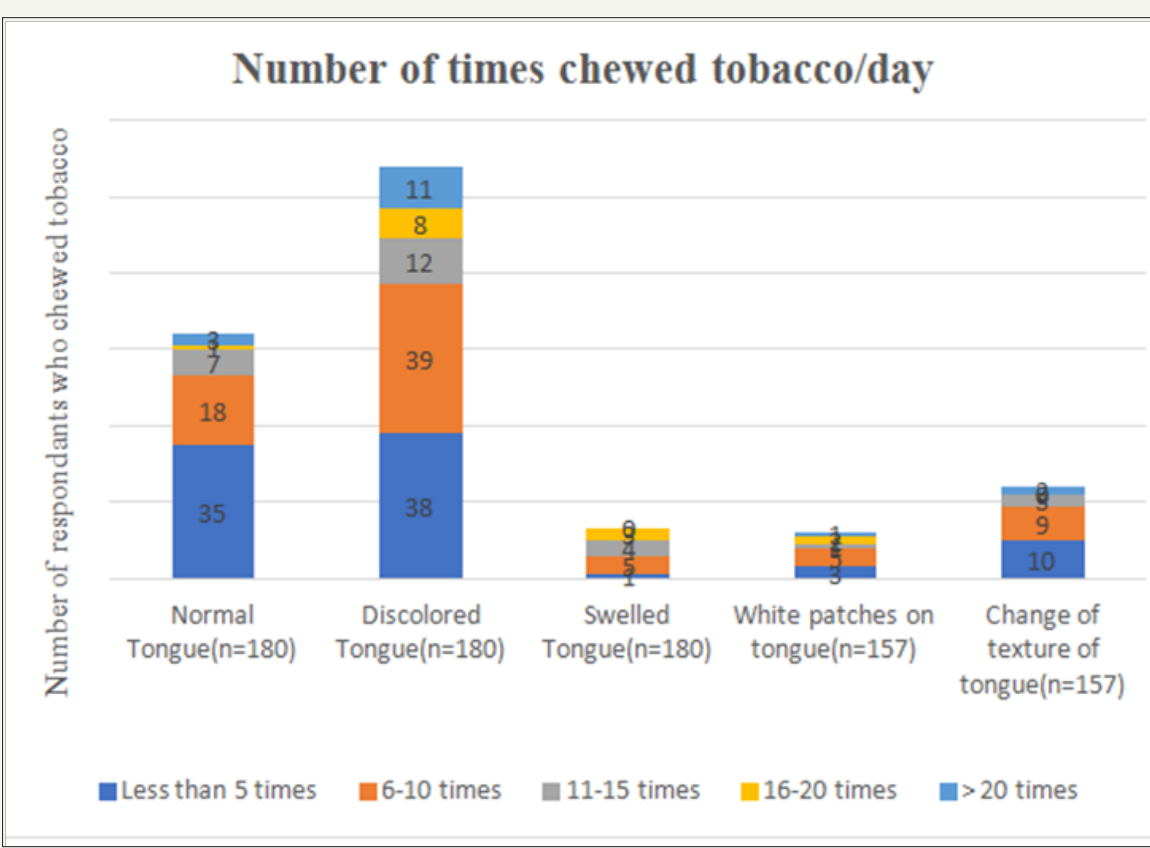

Figure 1: Statistically significant values were for normal buccal mucosa $06-10(p=0.007)$, white patch on buccal mucosa 11 $15(\mathrm{p}=0.0043)$, swelled buccal mucosa $11-15(\mathrm{p}=0.002)$. 


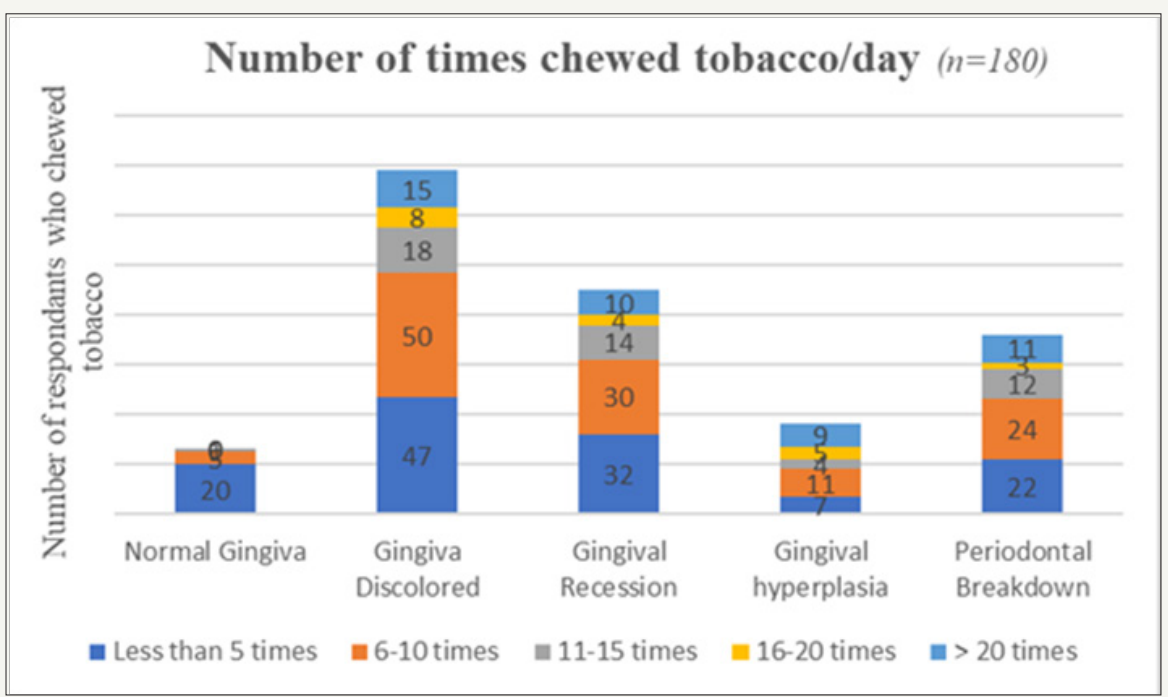

Figure 2: Statistically significant values were for discolored gingiva $<5(p=0.001), 16-20(p=0.004)$.

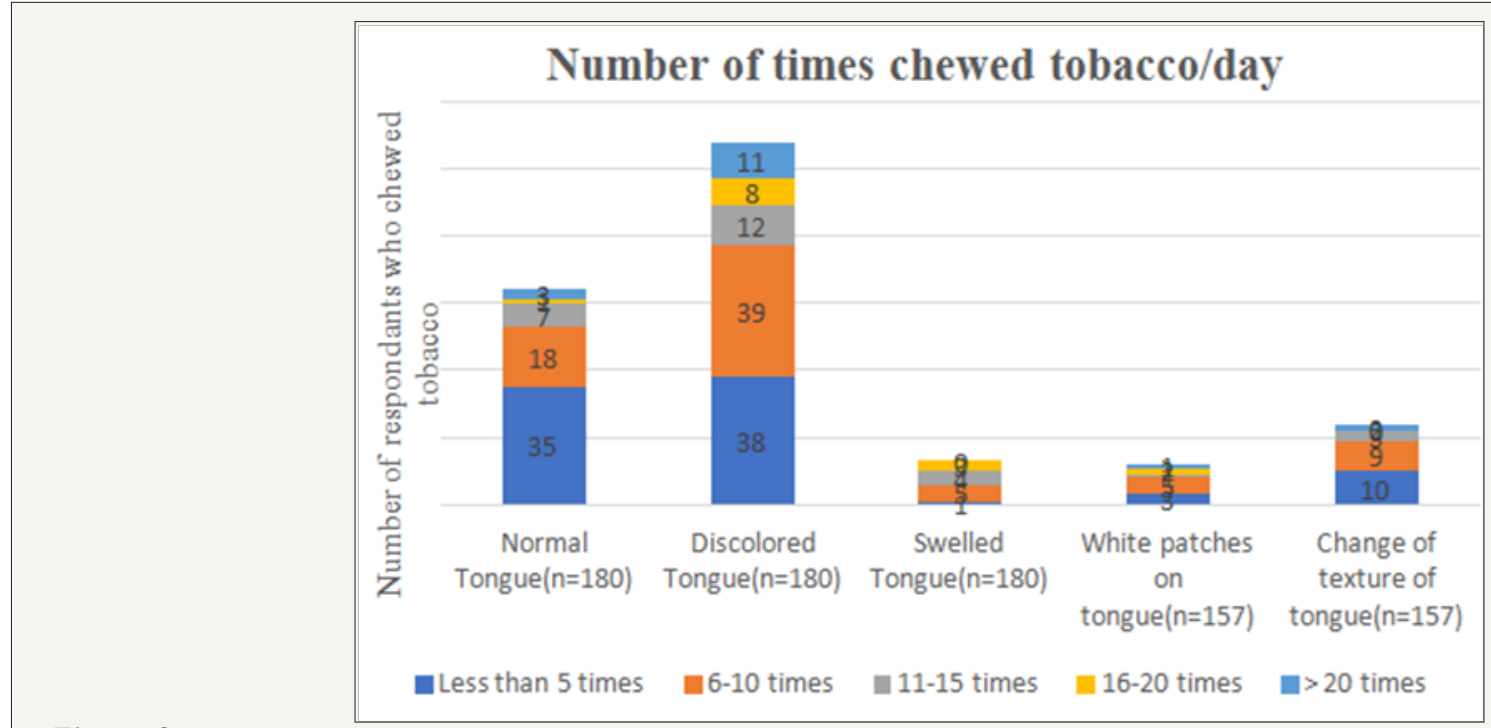

Figure 3:

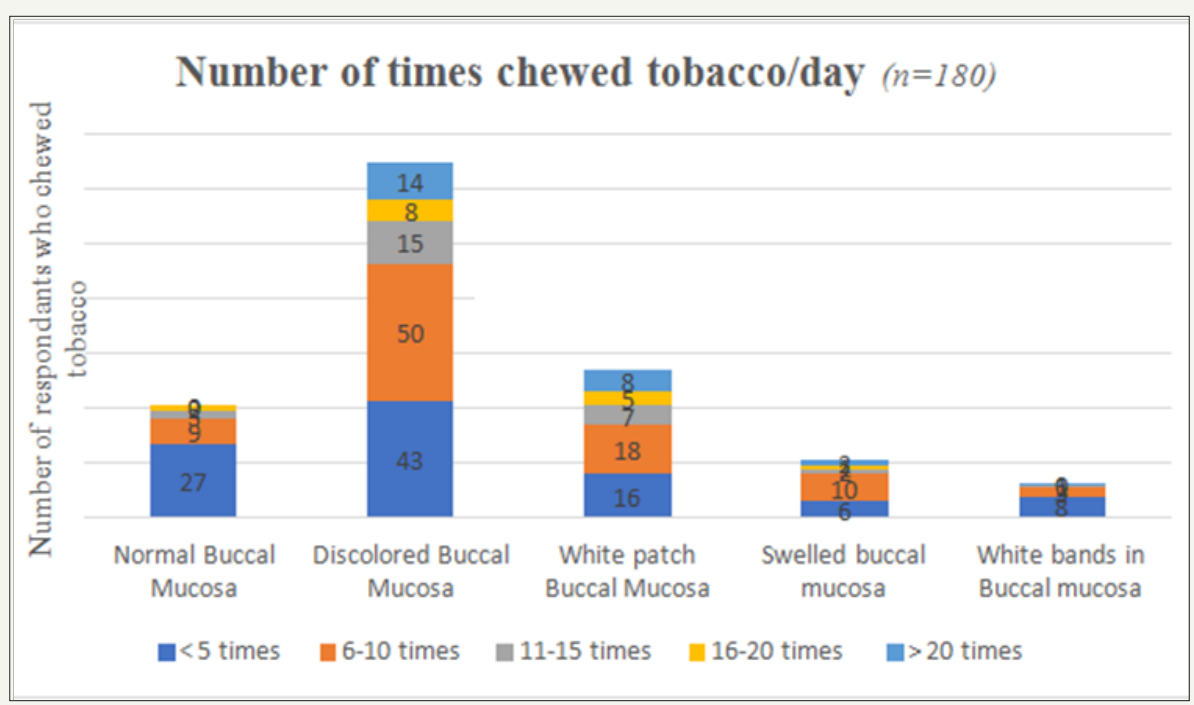

Figure 4: 


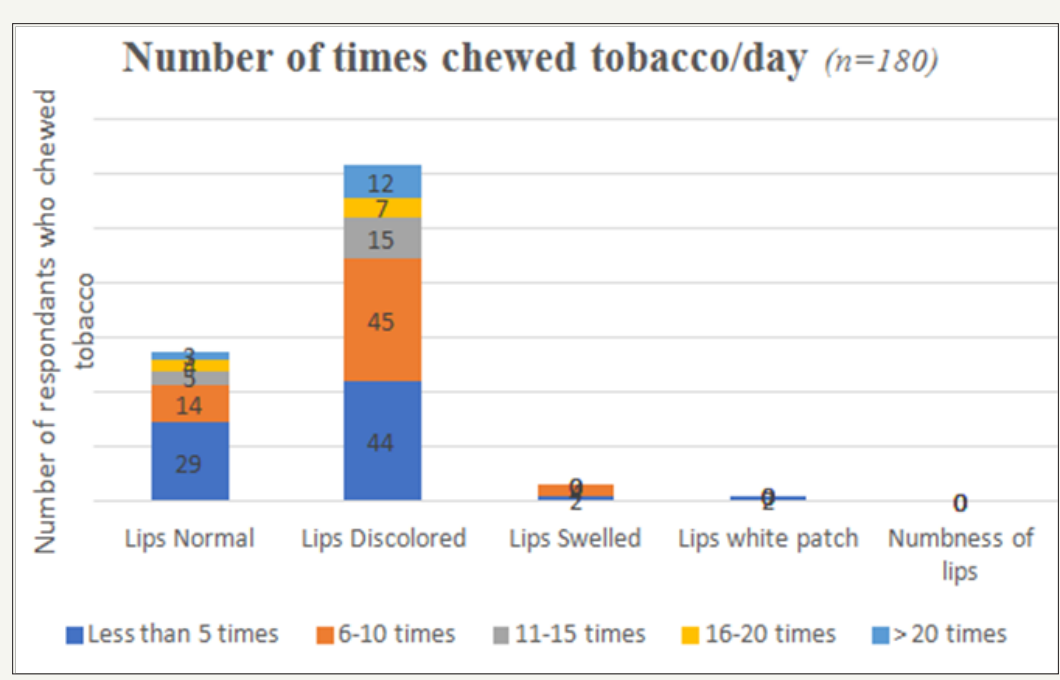

Figure 5:

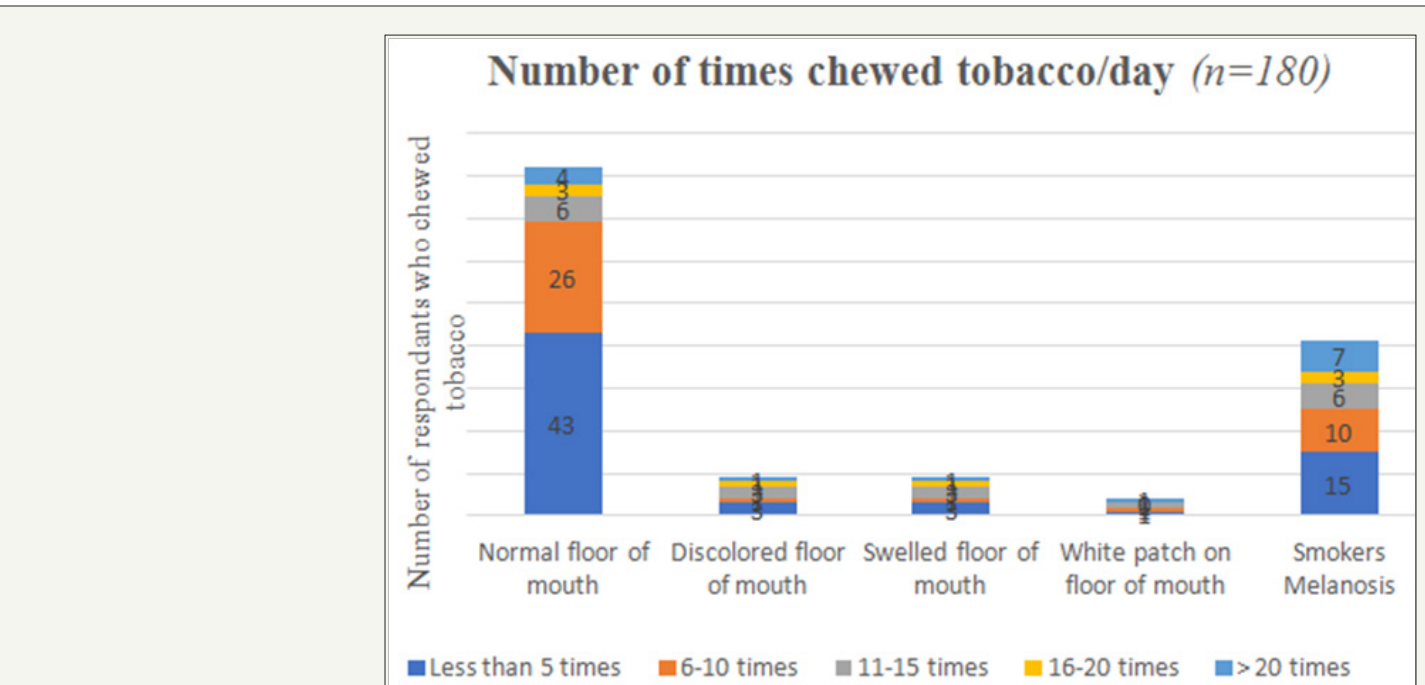

Figure 6:

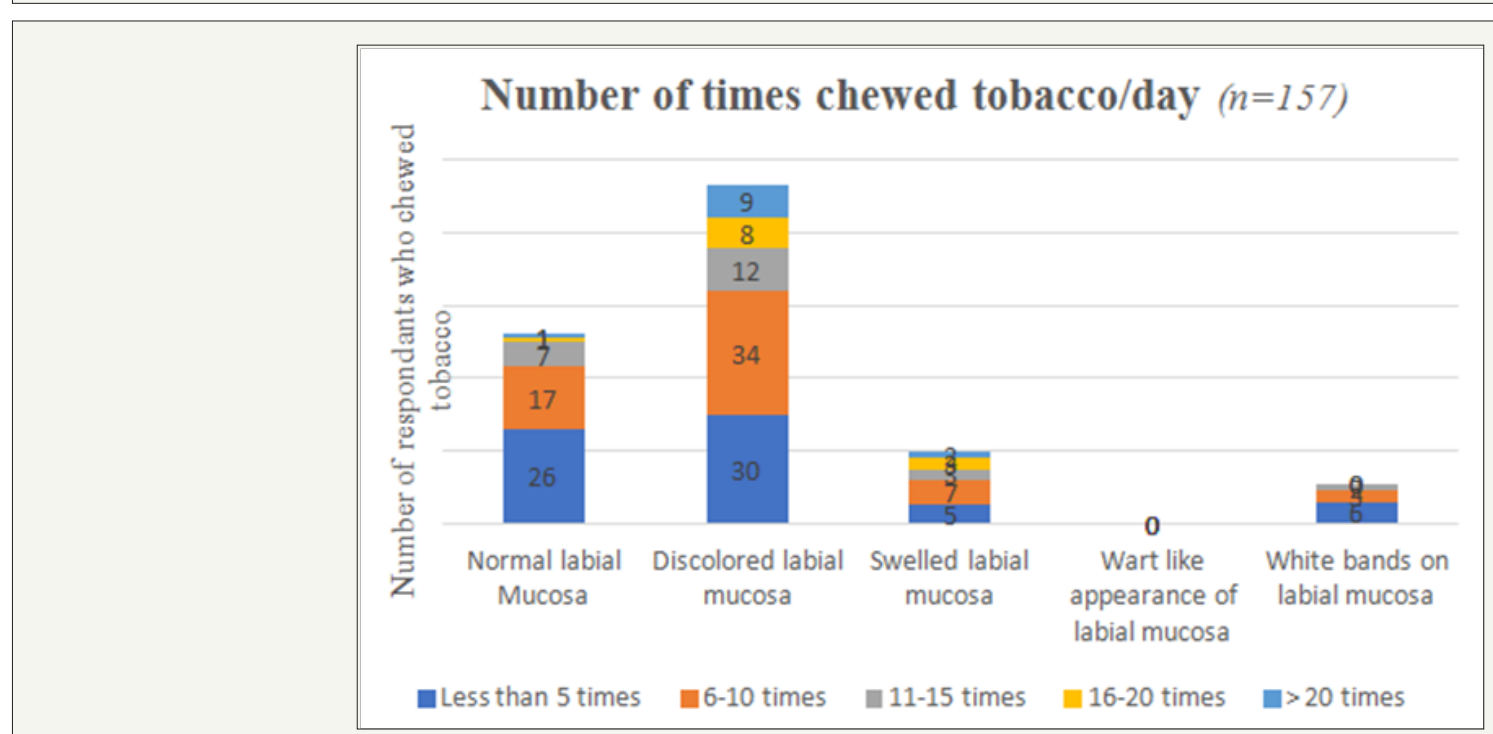

Figure 7: 


\section{Discussion}

According to D Grandy et al. [7] occurrence of lesions in oral mucosa occurs, at site where tobacco is placed and is largely dependent on duration and number of tobacco used [7]. With respect to demographic factors respondents having high school and undergraduate education accounted for highest number of tobacco users. This is in line with study by Shayam Sundar et al. [8] who reported $56.7 \%$ and $24 \%$ tobacco users having at least basic and high school education. This demonstrates a similar trend among tobacco users in South Asia. White patch on buccal mucosa was observed among $46 \%$ of participants who consumed smokeless tobacco with dose dependent parameters, similar to $47.4 \%$ subjects having leukoplakia in Shiyam Sundar et al. [8] study. Past studies have evaluated oral mucosal lesions due to smokeless tobacco, based on amount of time tobacco kept at a specific site in buccal mucosa or used in a year or months. Present study evaluated oral lesions based on dose dependent and number of times respondents kept tobacco in mucosa. Discoloration of oral mucosa was highest among respondents, with major bulk contributed by individuals consuming smokeless tobacco 5 to 10 times in a day. This has not come as a surprise due to fact that smokeless tobacco use results in change in area of vicinity where it is held. The severity of discoloration depends upon type of smokeless tobacco leaf versus fine cut, brand of tobacco use, size of smokeless tobacco that is kept under mucosa and duration it is kept. This has been confirmed by $\mathrm{D}$ Grady etal. [7] and others who stated oral lesions have an association with amount \& duration of tobacco use [4,9-11]. Majority of oral lesions observed in current study were among respondents who kept at least 5-10 times smokeless tobacco in their mouth. Similar trend was observed in a study by D Grady et al. [7] who observed individuals that kept tobacco in their mouth for 3- 4hrs and 4-5 packs to be $83.8 \%$. This trend of increase in number and duration of smokeless tobacco to be associated with increase risk for oral lesions has been reported by many researchers in similar studies [4,9-11]. With respect to effects on gingiva and periodontium, respondents that consumed 5-10 times smokeless tobacco in a day had the highest gingival discoloration, recession and periodontal breakdown. Robert 0 Greer et al. [4] and Van Wyk et al. [12] also reported high frequency of periodontal breakdown and gingival recession associated with increased exposure to smokeless tobacco $[12,13]$. This high frequency of periodontal and gingival lesion was highest for individuals that consumed smokeless tobacco at least five times a day. Periodontal destruction due to smokeless tobacco was observed in adults group, which is supported by Greer et al. [4] who stated advanced periodontal destruction, severe and hard tissue changes are accounted by long term use of smokeless tobacco and these features are classically observed among adults. Severity and clinical oral lesions observed among smokeless tobacco users is largely dependent upon abrasive quality, content of tobacco, chemical composition and processing that varies widely among different parts of the globe [14]. Pindborg et al. [15] reported characteristics pumice like appearance of oral mucosal lesions due to long term use of smokeless tobacco. In our study none of the subjects were observed to have this of characteristic oral appearance. Green [7] and Poulson [4] also stated absence of such oral lesions in his study. This can be due to different composition and processing of smokeless tobacco. Current study is a small effort to discriminate oral lesions as a result of use of smokeless tobacco.

The study has revealed premalignant oral lesions to be associated with smokeless tobacco as compared to cigarette smoke since smokeless tobacco has thirty different cancer-causing agents and the fact that it spends more time in mouth than cigarette smoke, that otherwise has increased susceptibility for lung cancer.

Further studies including other factors such as socioeconomic status, ethnicity and incorporating more number of participants including different provinces of Pakistan will help in further confirming our findings and report oral effects of frequency of smokeless tobacco at a national level.

\section{References}

1. Patel P, Patel V (2011) Oral mucosal lesions among residence of a town in north Gujarat. National Journal of Medical Research 1(1): 3-6.

2. Sudhakar S, Praveen Kumar B, Prabhat M (2011) Prevalence of oral mucosal changes in Eluru, Andhra Pradesh (India)-An institutional study. J Oral Health Comm Dent 5: 42-46.

3. Sridharan G (2014) Epidemiology, control and prevention of tobacco induced oral mucosal lesions in India. Indian J Cancer 51(1): 80-85.

4. Greer RO, Poulson TC (1983) Oral tissue alterations associated with the use of smokeless tobacco by teen-agers: Part I. Clinical findings. Oral Surgery, Oral Medicine, Oral Pathology 56(3): 275-284

5. Mishra GA, Pimple SA, Shastri SS (2012) An overview of the tobacco problem in India. Indian Journal of Medical and Paediatric Oncology 33(3): 139-145.

6. Stepanov I, Jensen J, Hatsukami D, Hecht SS (2008) New and traditional smokeless tobacco: comparison of toxicant and carcinogen levels. Nicotine Tob Res 10(12): 1773-1782.

7. Grady D, Greene J, Daniels T, Ernster V, Robertson P, et al. (1990) Oral mucosal lesions found in smokeless tobacco users. J Am Dent Assoc 121(1): 117-123.

8. Behura SS, Masthan MK, Narayanasamy AB (2015) Oral mucosal lesions associated with smokers and chewers-a case-control study in chennai population. J Clin Diagn Res 9(7): 17-22.

9. Wolfe MD, Carlos JP (1987) Oral health effects of smokeless tobacco use in Navajo Indian adolescents. Community Dentistry and Oral Epidemiology 15(4): 230-235.

10. Hirsch JM, Heyden G, Thilander H (1982) A clinical, histomorphological and histochemical study on snuff-induced lesions of varying severity. Journal of Oral Pathology \& Medicine 11(5): 387-398.

11. Poulson TC, Lindenmuth JE, Greer RO (1984) A comparison of the use of smokeless tobacco in rural and urban teenagers. CA: a cancer journal for clinicians 34(5): 248-261

12. Van Wyk C (1966) The oral lesion caused by snuff. A clinico-pathological study. The Journal of the Dental Association of South Africa=Die Tydskrif van die Tandheelkundige Vereniging van Suid-Afrika 21(4): 109-116.

13. Christen AG, Armstrong WR, McDaniel RK (1979) Intraoral leukoplakia, abrasion, periodontal breakdown, and tooth loss in a snuff dipper. J Am Dent Assoc 98(4): 584-586.

14. Roed Petersen B, Pindborg J (1973) A study of Danish snuff-induced oral leukoplakias. Journal of Oral Pathology \& Medicine 2(6): 301-313.

15. Pindborg J, Reibel J, Roed-Petersen B, Mehta F (1980) Tobacco-induced changes in oral leukoplakic epithelium. Cancer 45(9): 2330-2336. 
Creative Commons Attribution 4.0 International License

For possible submissions Click Here

Submit Article
MRD Modern
Research
in Dentistry

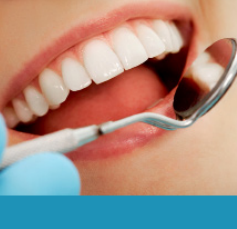

\section{Modern Research in Dentistry}

\section{Benefits of Publishing with us}

- High-level peer review and editorial services

- Freely accessible online immediately upon publication

- Authors retain the copyright to their work

- Licensing it under a Creative Commons license

- Visibility through different online platforms 